\title{
Application of Reticulated Metal Foam to Gas Fired Infrared Burners
}

\author{
Edward J. Cookson and Donald E. Floyd II \\ Porvair 'Advanced Materials \\ Hendersonville, North Carolina 28792,USA
}

(Received March 24, 2006: final form April 9, 2006)

\begin{abstract}
Reticulated metal foams have been shown to have advantages over alternative radiating media for gas fired radiant burners. This paper presents the experimental results of gas fired infrared emitters made from MetFlameß, an open cell reticulated FeCrAIY (an iron based high temperature alloy) foam. Emitters with pore size of about $420 \mu \mathrm{m}$ and porosity of $95 \%$ are studied at varying heat rates and equivalence ratios. The performance of MetFlame burners is compared to gas fired infrared burners with ported ceramic tile and sintered metal fiber emitters. The result of this study is an infrared burner material with significantly higher efficiency than conventional ceramic tile burners with lower NOx output. Metal foam burners also offer a much faster response time than ceramic tile burners. MetFlame burners also demonstrate higher efficiency than radiant burners made from sintered or knitted metal fibers.
\end{abstract}

Keywords: metal foam, combustion, infrared, low NOx, high efficiency

\section{INTRODUCTION}

Gas-fired radiant burners with many types of emitters have been investigated in the past for all manner of commercial and industrial applications. A suitable radiant burner material will support combustion without flame lift-off or flashback, withstand thermal shock during cyclic operation. An ideal burner material will produce very little NOx and convert the maximum possible fuel input to radiant energy

Ported ceramic tile emitters are widely used in commercial applications such as space heating and commercial cooking, and are the least expensive radiant emitter material. However, they suffer from flashback and thermal shock at high heating rates $/ 2 /$. Reticulated ceramic foam, similar to that used for molten metal filtration, has been studied as an emitter. Reticulated ceramic foam emitters are capable of low NOx operation and high radiant efficiency since combustion occurs within the cellular structure rather than on the surface. Unfortunately, ceramic foam emitters can suffer from the same thermal shock issues as ported ceramic tiles $/ 3,4 /$.

Sintered metal fiber emitters have found favor in the paper industry for coating and drying processes and have led to significant increases in productivity over the last 30 years $/ 3 /$. Metal fiber emitters suffer none of the thermal shock or flashback problems of ported ceramic tiles $/ 2 /$. Metal fiber also exhibits a higher emissivity than ceramic emitters $/ 5,6 /$ allowing high radiant output at lower surface temperatures. Metal foam emitters present a promising step forward, combining the structure of reticulated ceramic foam burners with the

\footnotetext{
• Correspondence to Edward Cookson, Email: tcookson@pamus.com
} 
higher emissivity $/ 7 /$ and thermal shock resistance of metal fiber burners.

MetFlame metal foam emitters are manufactured via the Astromet process, a powder metallurgy technique wherein a polyurethane foam precursor is coated with a slurry of metal powder and organic binder $/ 8 /$. Using this process, the pore size and void fraction can be independently controlled to fine tune the porous behavior for any application. Laboratory and field testing have shown the combination of $420 \mu \mathrm{m}$ pore size and $5 \%$ relative density of MetFlame yield an extremely efficient, responsive, and flashback resistant infrared emitter for premixed, or power, burner applications. The open cell structure of MetFlame is shown in Fig. 1.

\section{COMPARATIVE TEST APPARATUS AND EXPERIMENTAL METHOD}

Customers have requested performance comparisons of our MetFlame burner plates to their existing technology in these key areas:

- Surface Temperature
- Nitrogen Oxide and Nitrogen Dioxide (NOx) Emissions

- Cold start-up response time

\subsection{Radiant Burner Test Apparatus}

The surface temperature is the easiest of the three parameters to measure. A type $\mathrm{K}$ thermocouple is held in contact with the burner surface for the duration of each test. The average steady state temperature is calculated from the recorded data after each test is complete.

A pair of Teledyne API gas analyzers measures exhaust concentrations, defined as the volume fraction of each component of the exhaust gas. Exhaust gas is continuously sampled from the burner face with a stainless steel probe. The gas sample is cooled, filtered, and dehumidified to provide a clean dry sample for analysis. The concentrations of nitrogen oxides (NOx), carbon monoxide $(\mathrm{CO})$, carbon dioxide $\left(\mathrm{CO}_{2}\right)$, and oxygen $\left(\mathrm{O}_{2}\right)$ in the exhaust are calculated by the analyzer and recorded continuously throughout the entire test. Again, average steady state values for each are determined after each test is complete. The

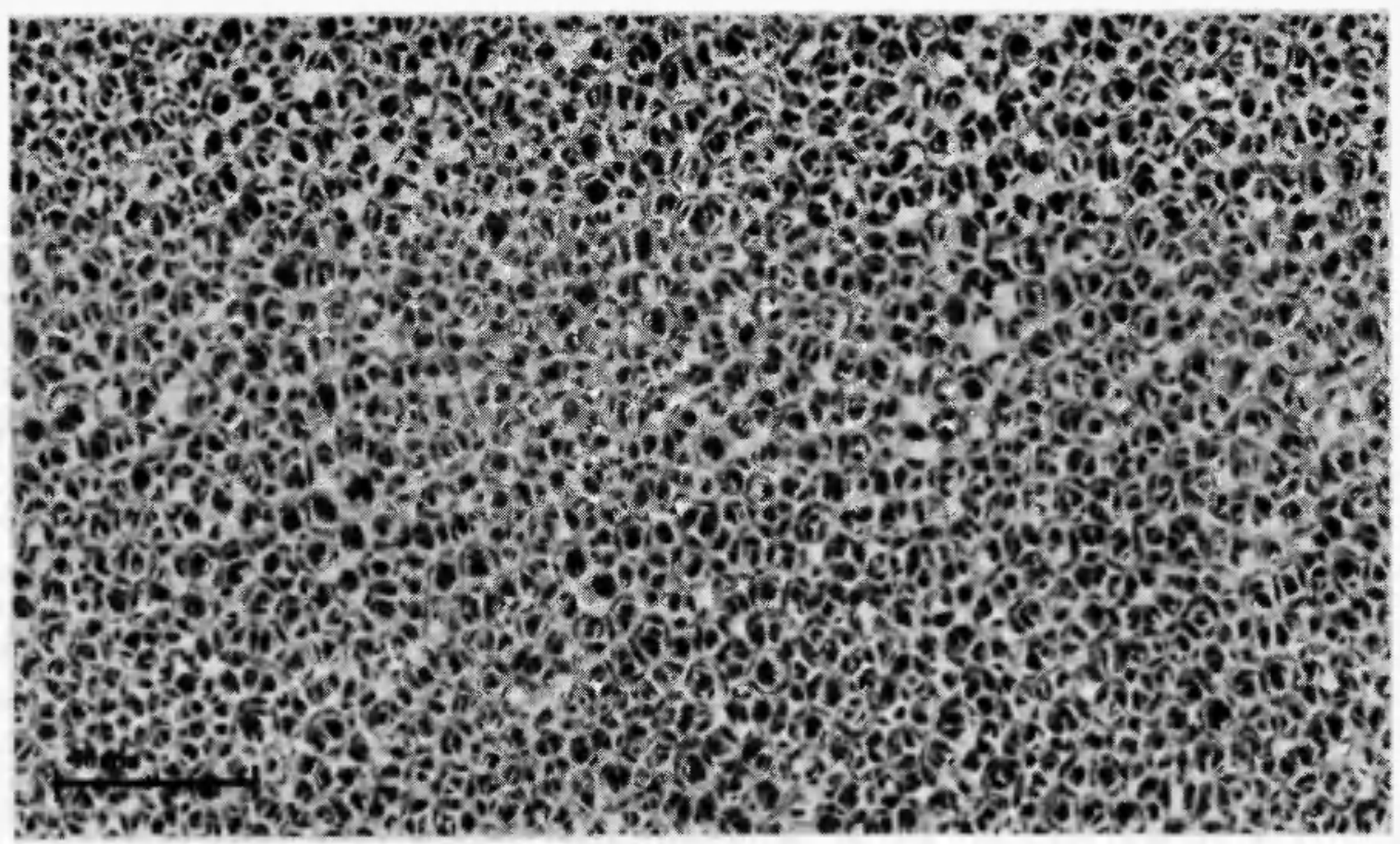

Fig. 1: Structure of MetFlame Open Cell Reticulated Metal Foam. 
measured concentrations appear quite sensitive to the position of the probe relative to the burner. This is especially true regarding the vertical distance from the probe to the burner face. The position and height of the probe are checked before each test to ensure consistent readings. All samples for these tests were drawn $25 \mathrm{~mm}$ above the center of the burner face. Generally $\mathrm{CO}, \mathrm{CO}_{2}$, and NOx measurements decrease as the distance above the plate increases. This is presumably due to dilution of the exhaust gases with secondary air from the surroundings.

\subsection{Ceramic Tile Comparative Test Conditions}

Gas flow is controlled using an Omega FMA-2400 series mass flow controller with a maximum range of about $1.5 \mathrm{~kg} / \mathrm{hr}$. Airflow is controlled with a Brooks thermal mass flow controller. The use of two mass flow controllers allows testing to be run at a wide range of flows and mass air-fuel (MAF) ratios. An air-fuel ratio of about $\mathbf{1 7 . 2}$ is the stoichiometric, or theoretically ideal, air fuel ratio for the combustion of methane. This is sometimes referred to as $100 \%$ theoretical air. Combustion analyses often refer to theoretical air or excess air rather than the MAF ratio. Excess air is simply theoretical air $100 \%$. MAF ratios slightly above and below stoichiometric were examined in these tests. The ranges tested are listed in Table 1.

\section{Table 1}

Experimental Gas Supply and Air-Fuel Ratios During Infrared Burner Testing.

\begin{tabular}{|l|c|c|c|}
\hline & Gas Supply & $\begin{array}{c}\text { Mass Air- } \\
\text { Fuel Ratio }\end{array}$ & Theoretical Air \\
\hline Low & $182 \mathrm{~kW} / \mathrm{m}^{2}$ & $15.0-20.5$ & $87 \%-120 \%$ \\
\hline High & $266 \mathrm{~kW} / \mathrm{m}^{2}$ & $15.4-21.1$ & $89 \%-123 \%$ \\
\hline
\end{tabular}

Gas-fired heating equipment is almost always intended to run "lean", that is with greater than $100 \%$ theoretical air. Typical values are $105-110 \%$, but exact values for each customer are not known. While it is true that burners are intended to run with greater than $100 \%$ theoretical air, they can often be run "rich" with less than $100 \%$. This could be due to deposits in the jet or manifold, incorrect fuel pressure, or damage to the burner. Tests are conducted with MetFlame burners in both lean and rich combustion to investigate the performance of the burner in all possible modes of operation.

\subsection{Metal Fiber Comparison Test Conditions}

The metal fiber burner comparison test condition is presented in Table 2. The measurement and burner control apparatus are the same as for the ceramic tile comparison tests presented earlier.

Table 2

Experimental Gas Supply and Air-Fuel Ratios During Infrared Burner Testing.

\begin{tabular}{|c|c|c|}
\hline Gas Supply & $\begin{array}{c}\text { Mass Air-Fuel } \\
\text { Ratio }\end{array}$ & Theoretical Air \\
\hline $260 \mathrm{~kW} / \mathrm{m}^{2}$ & $17.0-18.7$ & $90 \%-125 \%$ \\
\hline
\end{tabular}

\section{RESULTS AND DISCUSSION}

\subsection{Burner Plate Surface Temperature}

As one would expect, the average surface temperature of the burner plate was highest at the highest input rate, $266 \mathrm{~kW} / \mathrm{m}^{2}$, around $100 \%$ theoretical air. As theoretical air increases beyond $100 \%$, the burner temperature drops as convection carries away more heat.

MetFlame emitters operate as much as $50^{\circ} \mathrm{C}$ hotter than ceramic tiles at all input rates above $160 \mathrm{~kW} / \mathrm{m}^{2}$. This is due largely to the fact that the flame front resides just below the surface of the reticulated foam emitter. The surface layer of the emitter captures waste heat from the escaping exhaust gases and achieves higher operating temperatures for the same gas input. Fig. 2 illustrates the average steady-state temperature of both MetFlame and ceramic tile radiant burners.

MetFlame radiant burner emitters operate at a much higher temperature at all air-fuel ratios than either sintered or knitted metal fiber emitters. As illustrated in Fig. 3, the reticulated foam structure of the MetFlame material results in up to $200{ }^{\circ} \mathrm{C}$ higher surface temperatures than knitted metal fibers, and up to $100{ }^{\circ} \mathrm{C}$ higher surface temperatures than sintered metal fibers. 


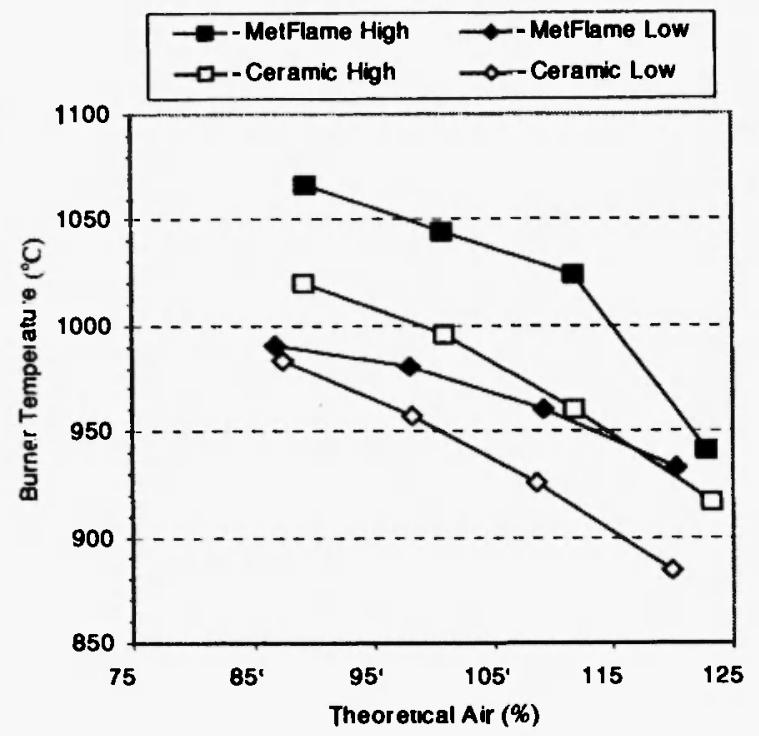

Fig. 2: Average Steady State Burner Surface Temperature Values for Metal Foam vs. Ceramic Tile Burner ComparisonTesting.

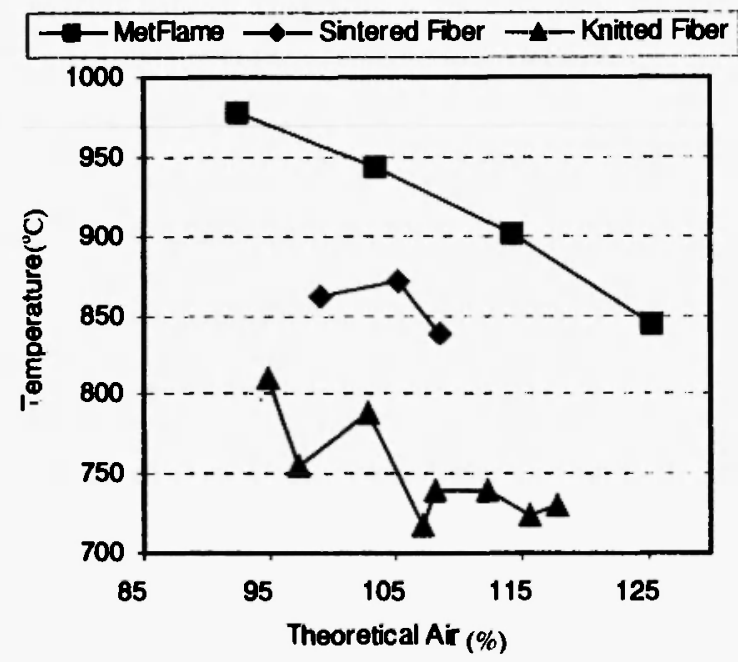

Fig. 3: Average Steady State Burner Surface Temperature Values for Metal Foam vs. Metal Fiber Burner Comparison Testing.

\subsection{Nitrogen Oxides Emissions}

Average exhaust $\mathrm{NO}_{\mathrm{x}}$ concentrations are shown below in Fig. 4 for both MetFlame metal foam and traditional ceramic tile infrared burners. $\mathrm{NO}_{\mathbf{x}}$ data are often presented on a standard $0 \%$ or $3 \%$ excess $\mathrm{O}_{2}$ basis. Since both rich and lean conditions were tested, the data

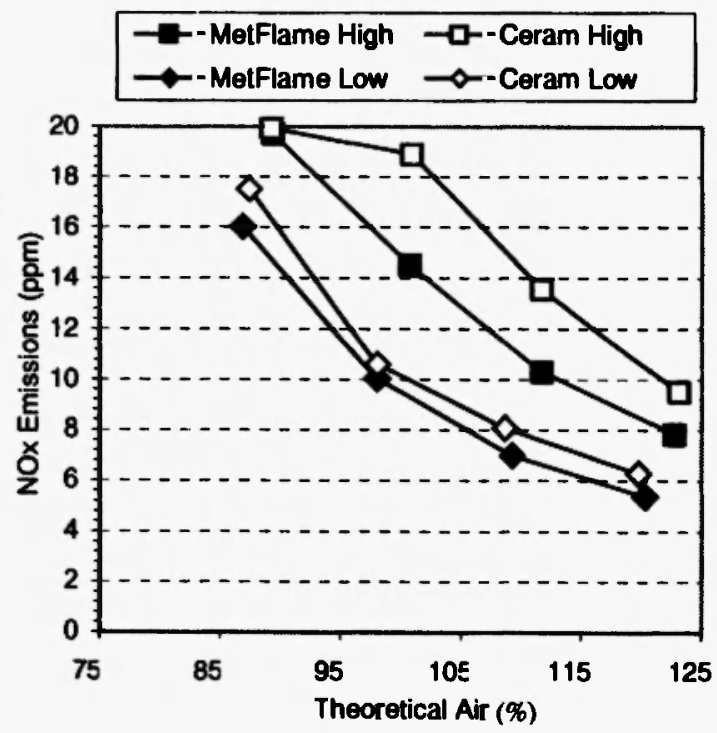

Fig. 4: Average Steady State $\mathrm{NO}_{\mathrm{x}}$ Concentration for Metal Foam vs. Ceramic Tile Burner Comparison Testing.

are presented as measured, without conversion. $\mathrm{NO}_{\mathbf{x}}$ concentrations are greater at higher fuel flow rates, and generally decrease with increasing theoretical air. MetFlame burners exhibit lower $\mathrm{NO}_{\mathrm{x}}$ emissions than ceramic tiles for the low and high intensity test conditions. Generally $\mathrm{NO}_{x}$ is formed at high temperature, so at higher equivalence ratios not only is exhaust gas more dilute, but less $\mathrm{NO}_{\mathbf{x}}$ is being formed at the lower burner temperature. The improved performance of MetFlame versus ceramic tile burners is doubly notable since the MetFlame burners exhaust lower concentrations of $\mathrm{NO}_{x}$ at the same gas input even though they operate at a higher temperature than ceramics.

The average exhaust $\mathrm{NO}_{\mathbf{x}}$ concentrations for metal fiber comparative testing are shown below in Fig. 5 . Again, since both rich and lean conditions were tested, the data are presented without conversion to an air-free standard. As with ceramic tile testing, NO concentrations decrease with increasing theoretical air. MetFlame burners exhibit higher $\mathrm{NO}_{\mathbf{x}}$ emissions than knitted or sintered metal fibers for the selected test condition. It may be possible to tune the MetFlame burners for lower $\mathrm{NO}_{\mathbf{x}}$ operation, since experiments have shown some dependence on pore size and porosity in $\mathrm{NO}_{\mathbf{x}}$ production. 


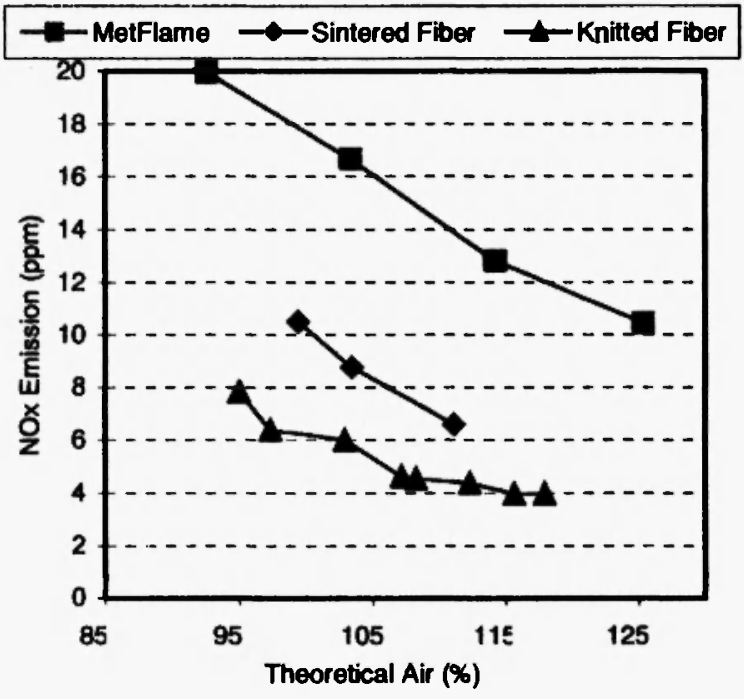

Fig. 5: Average Steady State NOx Concentration for Metal Foam vs. Metal Fiber Burner Comparison Testing.

\subsection{Transient Response Time}

In addition to operating at a higher temperature with equivalent gas input, MetFlame metal foam burners reach their operating temperature after ignition. A typical heating cycle is shown in Fig. 6 for both MetFlame and ceramic tile emitters operating at 266 $\mathrm{kW} / \mathrm{m}^{2}$. Rapid heating yields to fuel savings in cyclic processes.

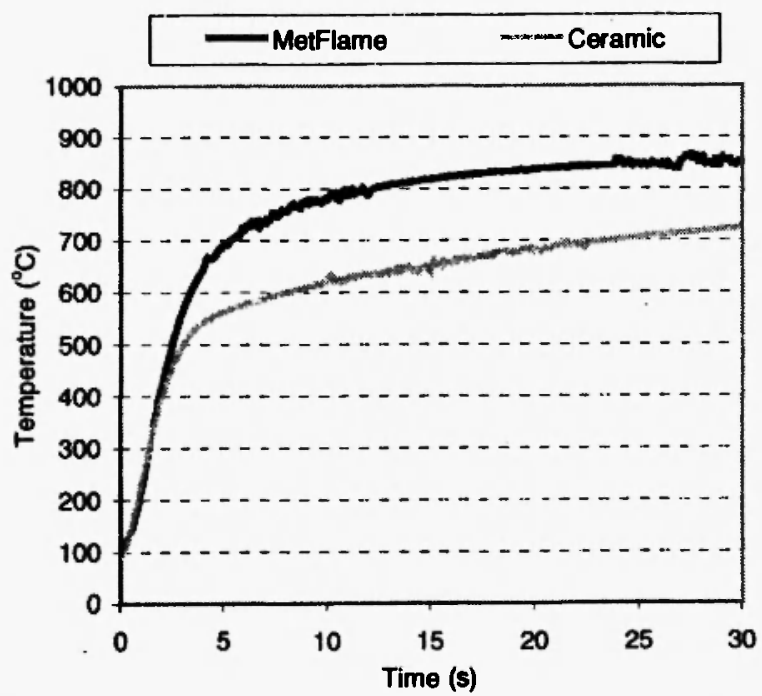

Fig. 6: Transient Temperature Profile - Heating from Cold Start at $266 \mathrm{~kW} / \mathrm{m}^{2}$.
MetFlame burners also cool down from radiating temperature to room temperature in less time that ceramic tile emitters. The temperature profiles of metal foam and ceramic tile emitters after fuel shutoff are shown in Fig. 7.

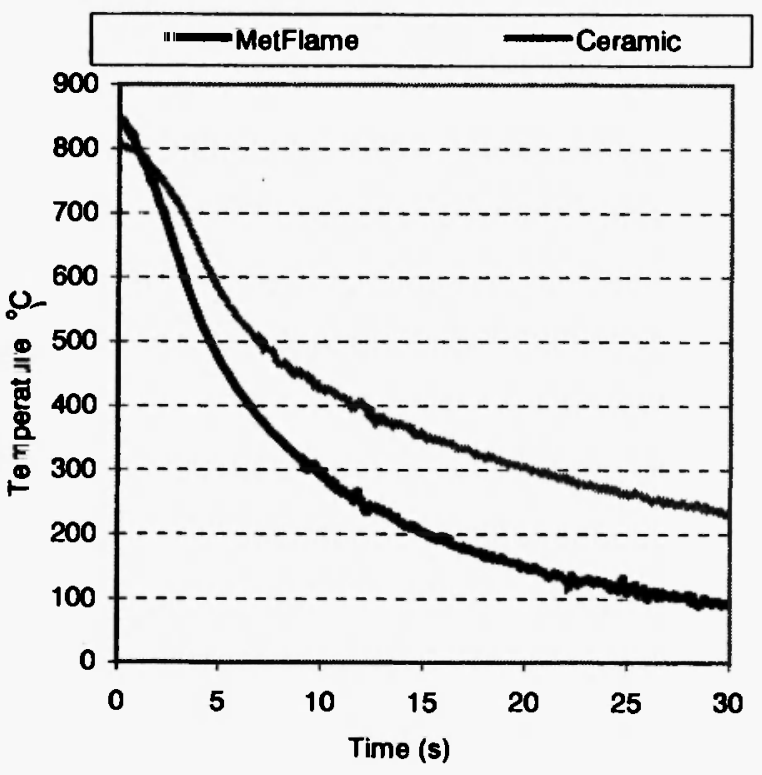

Fig. 7: Transient Temperature Profile - Cooling from Steady State Operation at $266 \mathrm{~kW} / \mathrm{m}^{2}$.

\section{CONCLUSIONS}

This paper provides performance data for MetFlame gas fired infrared burners. MetFlame metal foam burners operate at higher temperatures than ceramic tile burners at the same input. They respond to changes in input more quickly, resulting in more efficient operation, and they produce lower $\mathrm{NO}_{\mathbf{x}}$ emissions than ceramic tile infrared burners under the same operating conditions. While the fiber burners in this case produced lower NOx, it may be possible to tune the metal foam burners for even lower NOx by changing the pore size or porosity. MetFlame burners also achieve higher temperatures than either knitted fiber or sintered fiber infrared burners constructed from the same alloy. 


\section{REFERENCES}

1. Tidball, Donaldson, \& Gotterba. Radiant Burner Technology Base - Burner Research \& Development. Chicago: Gas Research Institute (GRI 89/0253).

2. Sommer \& Aust. IR Drying Concepts for High Energy Yield Meet Rising Demands on Coat Quality and Production Speed. $18^{\text {th }}$ PTS Coating Symposium, Munich, 1997.

3. Haack, David. Application of Reticulated Ceramic Foam to Radiant Burners, Vol 1. Chicago: Gas Research Institute (GRI-96.0255.1).
4. Hsu, Pei-feng. A Low NOx Porous Ceramics Burner Performance Study. California Energy Commission, EISG Program (52930A/02-14).

5. Kanthal, 2001. Kanthal Heating Alloys Handbook. Kanthal, AB.

6. Incropera \& DeWitt. Introduction to Heat Transfer, 3rd Ed. New York: John Wiley \& Sons, 1996.

7. Zhao, et al. "Thermal Radiation in Ultralight Metal Foams with Open Cells", Int. J. HeatMass Trans 47, 2927-2939 (2004).

8. Astromet, Inc. 1997. Porous Materials and Method for Producing. World Patent WO 97/31738. 